\title{
Which factors may influence the implementation of drug dispensing in community pharmacies? A qualitative study
}

\section{Sabrina Cerqueira-Santos}

Universidade Federal de Sergipe

Kérlin Stancine Santos Rocha

Universidade Federal de Sergipe

Dyego Carlos Souza Anacleto Araújo

Universidade Federal de Sergipe

Genival Araujo Santos Júnior

Universidade Federal do Espirito Santo

Pedro Wlisses dos Santos Menezes

Universidade Federal de Sergipe

Júlia Mirão Sanchez

Universidade Federal de Sergipe

Alessandra Rezende Mesquita

Universidade Federal de Sergipe

Divaldo Lyra Jr ( $\sim$ lepfs.ufs@gmail.com )

Universidade Federal de Sergipe https://orcid.org/0000-0002-0266-0702

\section{Research}

Keywords: implementation science, drug dispensing, community pharmacy, qualitative research

Posted Date: August 4th, 2020

DOl: https://doi.org/10.21203/rs.3.rs-51203/v1

License: (a) This work is licensed under a Creative Commons Attribution 4.0 International License. Read Full License 


\section{Abstract}

Background: Implementation of clinical pharmacy services, such as drug dispensing, is a complex process. It is necessary to understand the challenges associated with this practice from the perspective of the actors involved to help ensure optimal service provision. Thus, this study aimed to understand the factors that may influence the implementation of drug dispensing in community pharmacies, according to the perceptions of pharmacists.

Methods: This qualitative study was based on semi-structured, face-to-face interviews. The participants were pharmacists who worked in a chain of community pharmacies in Brazil, selected based on their direct participation in the implementation process. The interview recordings were transcribed full verbatim and were independently analyzed using thematic analysis, followed by consensus meetings between researchers. The factors identified by the participants were classified according to the Apoteca framework. This study was approved by the Committee of Ethics in Research and all participants signed an informed consent form.

Results: We conducted 18 interviews, with 47 factors that may influence the implementation of drug dispensing in community pharmacies being identified. These factors were allocated to seven categories: support from community pharmacy chain (4), pharmacy infrastructure (11), characteristics of the pharmacy, medicines and other health products (4), pharmacist (16), dispensing work process (2), pharmacy team (2), and patient (8). The classification of factors according to the Apoteca framework allocated most of them to administrative (14) and technical (14) domains, followed by attitudinal (13) and political (5) domains.

Conclusions: This study identified several factors that can influence the implementation of drug dispensing and classified them according to the domains of the Apoteca framework, highlighting the multifactorial nature of the implementation process. The results of this study can guide the planning of strategies aimed at providing efficient drug dispensing in community pharmacies.

\section{Contributions To The Literature}

- Our findings contribute to literature, since it includes new factors that may influence the implementation of clinical pharmacy services in community pharmacies.

- The implementation factors identified in this study can guide decisions-makers, managers, and pharmacists to plan strategies for all stages of implementation of drug dispensing, in order to improve this service and qualify the care provided to patients.

- The classification of factors according to the Apoteca framework can assist in the planning and implementation of specific strategies for a successful implementation and provide insights for other studies that aimed to implement clinical pharmacy services.

\section{Background}


Worldwide, drug dispensing is the most widespread service in community pharmacies. This service serves many people and can positively impact patients' health when carried out properly [1, 2]. In Brazil, there are more than 85,000 community pharmacies, in which more than 140,000 pharmacists work, mainly in the dispensing of drugs [3]. However, the quality of this service is inadequate in several countries due to a lack of effective dispensing models with clearly defined processes and outcome indicators $[4,5,6]$.

In community pharmacies, the implementation of clinical pharmacy services (CPS) causes changes in the pharmacists' behavior, organizational culture, and administrative processes, which are influenced by stakeholders' perceptions and motivations [7, 8]. In this context, implementation science promotes the systematic and qualified incorporation of health services in practice $[9,10]$. The implementation of CPS in community pharmacies, which include drug dispensing, is a complex process, the outcome of which can be influenced by numerous factors [11].

Implementation science is based on quantitative and qualitative methods that complement each other in order to broaden the understanding of processes and strategies necessary to implement a particular service, and to evaluate the results $[12,13]$. There have been numerous qualitative studies seeking to understand the factors that influence the implementation of CPS in community pharmacies; however, studies with a specific focus on drug dispensing are absent from the literature $[14,15,16]$. Thus, it is important to understand the different factors that can influence implementation processes of CPS including drug dispensing in order to facilitate it [11].

Recently, some studies have identified the need to improve drug dispensing with defined and documented work processes $[17,18]$. It is therefore necessary to reflect on the processes related to the dispensing practice and its implementation in relation to the actors involved. Thus, the aim of this study was to understand the factors that may influence the implementation of drug dispensing in community pharmacies, according to the perceptions of pharmacists.

\section{Methods}

\section{Study design}

A qualitative study design was employed involving semi-structured interviews with pharmacists to provide a comprehensive understanding of factors that may influence the implementation of drug dispensing in a chain of community pharmacies in Brazil. The interviews were conducted from November 2019 to January 2020.

\section{Study context and setting}

In Brazil, people have access to medicines through private community pharmacies and/or pharmacies belonging to the Brazilian Health System (SUS), free of charge. Nationally regulated licensure is needed to open and operate a community pharmacy in Brazil. Although pharmacy ownership is not restricted to 
pharmacists, a legally responsible pharmacist should be employed and be ever-present at the pharmacy during opening hours. There are no rules regarding the location of pharmacies in Brazil in relation to demographic and geographical criteria [19].

A private chain community pharmacy participated of the present study. The first pharmacy belonging to this chain was installed in Brazil in 1935, with approximately 1,400 currently operating across the country. The specific chain of pharmacies examined in this study was established in 2017, having 18 pharmacies located in the capital, which was the setting for the drug dispensing implementation process evaluated herein. The pharmacy team consisted of pharmacists, managers (not all of whom are pharmacists), and pharmacy assistants. In 2019, the Laboratory of Teaching and Research in Social Pharmacy (LEPFS) of the Federal University of Sergipe (UFS) established partnerships with this chain of community pharmacies aimed at implementing drug dispensing.

The implementation process will be based on the Methodology of Problematization with Maguerez Arc in association with the Apoteca framework $[20,21]$. This methodology has five steps: observation of reality, key points, theorizing, solution hypotheses, and application to reality $[22,23]$. This study incorporated the first stage of this methodology (observation of reality), through semi-structured interviews with pharmacists involved in the implementation process. It is worth mentioning that we intend on incorporating the other steps in future studies.

The research team in this study was composed of a general coordinator (DPLJ) with experience in CPS implementation, two senior researchers (ARM and GASJ), also with experience in the area, three research pharmacists (KSSR, SCS, and DCSAA), and two pharmacy students (JMS and PWSM).

\section{Participants}

One pharmacist from each of the 18 pharmacies, selected for convenience by managers, participated in this study. These 18 pharmacists were involved in the implementation process of drug dispensing.

\section{Data collection}

Semi-structured interviews were conducted with pharmacists using the recommendations proposed in the Consolidated Criteria for Reporting Qualitative Research (COREQ) [24]. This data collection method was chosen to include the varied experiences and perceptions of the participants. The interview guide was constructed during a brainstorming meeting between the research team (ARM, KSSR, and SCS), based on relevant literature $[25,26,27]$ and their clinical experiences.

One of the researchers (SCS) subsequently conducted a pilot test interview with one of the authors of the study (DCSAA). The final format of the interview guide was defined by the research team through consensus discussions (Appendix 1). All interviews were audio recorded and conducted in the community pharmacies by prior appointment, according to the interviewees' choice, in a reserved room, guaranteeing the confidentiality and freedom of expression of the participants. At the time of the interview, only the moderators and the pharmacist being interviewed were present. 
The interviews were conducted by two female researchers from the research team (KSSR and SCS), who had master's degree and previous experience with this type of data collection. The researchers had no relationship with the interviewees prior to study commencement. At the beginning of the interview, the moderators explained the research objectives and the participants agreed to collaborate by signing an informed consent authorizing the researchers to use their audio recordings. The researchers took field notes during the interviews.

\section{Data analysis}

The interviews were transcribed full verbatim and the data were initially analyzed independently by two researchers (KSSR and SCS), using thematic analysis [28], before a consensus meeting was held. The factors influencing the implementation of drug dispensing were categorized using an inductive approach [29]. After the categories were defined, the data were reviewed by two researchers (DCSAA and GASJ) and a careful review was subsequently carried out by two senior evaluators (ARM and DPLJ). After this process, critical analysis of the data was performed. All interviews were analyzed regardless of data saturation [30].

The factors identified in the study were classified by two researchers (KSSR and SCS), according to the Apoteca framework, which comprises the following domains: "attitudinal", "political", "technical", and "administrative". This conceptual framework emerged from systematic observation and immersion of our research group (LEPFS, UFS) in the implementation of CPS in various settings within the Brazilian Health System $[20,21]$. The aforementioned domains are defined as follows:

- Attitudinal domain: related to behavior, action, or reaction, and motivated by a feeling or opinion toward or of a particular fact or person; including internal and external motivation.

- Political domain: related to the relationships within a group or organization that allow particular individuals or groups to influence others (support).

- Technical domain: related to the CPS' own characteristics, as well as the skills and knowledge needed to perform them.

- Administrative domain: related to the administrative processes (organization and management) that are required to perform CPS.

\section{Concepts adopted in this study}

The concept of drug dispensing adopted in this study is based on that of previous literature, which highlighted key complementary components of this service [31,32,33]. Thus, drug dispensing is a clinical pharmacy service that ensures the provision of medicines and other health products through the analysis of technical and legal aspects of prescription, assessment of individual health needs, and performance of interventions in the medicine use process, which includes pharmaceutical counseling and documentation of the interventions made. 
Implementation factors are defined as elements that can moderate, either positively (facilitators) or negatively (barriers), the implementation of the services [11].

\section{Results}

Eighteen interviews were carried out, with an average duration of 28 minutes (min: 13'02"; max: 51'49"). The characteristics of the pharmacists who participated in the implementation process are described in Table 1.

\section{Factors that may influence the implementation of drug dispensing}

Forty-seven factors that possibly influence the implementation of drug dispensing were identified, and these were allocated to seven categories: support from the community pharmacy chain (4), pharmacy infrastructure (11), characteristics of the pharmacy, medicines and other health products (4), pharmacist (16), dispensing work process (2), pharmacy team (2), and patient (8). Table 2 presents the factors and categories that emerged from the interview, as well as the classifications derived from the Apoteca framework.

\section{i) Factors related to support from the community pharmacy chain}

Pharmacists reported that the institutional policy aimed at patient care, the support of managers, and the supply of training by the community pharmacy chain can be facilitators for implementing drug dispensing. In addition, they reported that managers guaranteed the autonomy of pharmacists to act clinically.

\section{ii) Factors related to pharmacy infrastructure}

Pharmacists reported that the presence of physical resources (adequate, wide, and air-conditioned pharmacy area) and materials (computers and internal systems for consulting information about medicines and about the patient, such as address, telephone, and purchase history) can facilitate the implementation of drug dispensing. However, the lack of a private area, internet access, and drug interaction programs can make patient care difficult.

Regarding human resources, the presence of a pharmacist throughout the pharmacy's opening hours was described as a positive factor. Most pharmacists reported that an insufficient number of pharmacy attendants can overwhelm the team and make it difficult to implement dispensing.

With regard to training and qualification of human resources, pharmacists highlighted insufficient clinical training and the gap between what is learned during undergraduate studies and the reality of a community pharmacy as a barrier. In this sense, pharmacists reported the need to complement their academic education with specialization courses. 
"Undergraduate pharmacy courses do not teach us how to provide dispensing in the pharmacy, rather, we are only taught the most technical and theoretical aspects of drugs. When we begin working in the community pharmacy, we panic!" (Pharmacist $A$ )

\section{iii) Characteristics of the pharmacy, medicines, and other health products}

The location of the community pharmacy was identified as a factor that could make it difficult to implement drug dispensing, in such cases where the pharmacy is located in a busy urban shopping mall, thereby having to accommodate a large number of patients and patient profiles. All pharmacists reinforced the difficulty with performing drug dispensing when there was a high number of patients in the pharmacy at one time.

"When there is a large number of patients in the pharmacy, we can only deliver the medication to the patient or the shopper [without counseling them]." (Pharmacist J)

Additionally, the type of dosage form has also been described as a factor that can influence the counseling provided to the patient and, consequently, the implementation process. Typically, when medicines with complex dosage forms are dispensed, pharmacists have reported that they tend to provide more patient counseling. In addition, the range of medicines and health products in the market has been described as a factor that can hinder implementation, since pharmacists always need to be up to date on market innovations.

\section{iv) Factors related to the pharmacist}

The number of clinical and logistical activities was described as a factor that may compromise the implementation of drug dispensing, due to the associated difficulty for pharmacists to perform all of their duties. However, the division of activities between the pharmacy team was reported as a positive point.

"Some days, I am checking the medicines that arrive at the community pharmacy and, at the same time, I am at the pharmacy counter. If a patient arrives and needs me, I will stop the checking [the medicines] and I will attend to the patient." (Pharmacist $P$ )

Pharmacists reported the need to develop and/or improve their knowledge (pharmaceutical legislation, pharmacotherapy, and foreign language), skills (communication with patients), and attitudes (interest, self-confidence, and initiative to provide the service) when dispensing drugs. These competencies have been reported as essential to identifying patients' health needs and making clinical decisions.

"Decision making depends on the situation of each patient. There are patients who don't need medication, they need referral to a physician. We have to make this assessment." (Pharmacist H)

Finally, pharmacists declared that motivation generated by their interaction with the patient (positive feedback and a good therapeutic relationship), the team (recognition of leadership role), and the other pharmacists (professional satisfaction) can boost the implementation of the service. 
"What motivates me is satisfaction. It is the patient really coming back to the community pharmacy to say that he or she has been feeling better and that I have made a difference in his or her life. I think this is very rewarding." (Pharmacist $C$ )

\section{v) Factors related to the dispensing work process}

The lack of a structured and systematic model that helps pharmacists during drug dispensing was cited as a factor that can hinder the implementation of the service. In addition, interviewees alluded to the use of telephone contact to obtain patient feedback on the medicine use process can facilitate the implementation process. However, it was pointed out that this strategy was performed only for patients who used antimicrobials.

\section{vi) Factors related to the pharmacy team}

Pharmacists described how the implementation of drug dispensing is facilitated when each member of the pharmacy team understands their role. For example, when a patient requests an over-the-counter medicine, the pharmacy assistant forwards the request to the pharmacist. Another positive factor reported was having good relations within the pharmacy team.

\section{vii) Factors related to the patient}

The interviewees reported that patients had characteristics (previous knowledge about pharmacotherapy, literacy, and age) and behaviors (interest, active participation in the service, and opinions on dispensing) that can influence the pharmacist's attitude when dispensing drugs and, consequently, in the service implementation. In addition, pharmacists pointed out that the expectations that patients have can generate negative feelings (shame, fear, and frustration), especially when the pharmacist's knowledge does not meet the patient's expectations. The pharmacists also stated that the implementation of drug dispensing can be influenced by the person receiving the care, that is, the pharmacist will adapt the process depending on whether they are attending to the patient, a family member, a caregiver, or another person unrelated to the patient but collecting medication on their behalf.

\section{Factor classification according to the Apoteca framework}

The factors were classified as administrative (14), political (5), technical (14), and attitudinal (13) domain (Table 2).

\section{Discussion}

The literature based on qualitative studies that identify factors that may influence the implementation of CPS is extensive $[14,15,25,27,34]$ which begs the question, why carry out more studies on this topic? We believe that drug dispensing, as a basic and integrated service to health care networks, has great potential to promote the rational use of medicines and to screen patients who need additional, more complex, CPS. The factors identified in this study were specific to drug dispensing, bringing to light new 
factors that can influence the implementation of CPS. In addition, the classification of factors according to the Apoteca framework showed their applicability in other settings, such as community pharmacy, and reinforced the multifactorial nature of the CPS implementation process [11, 35]. Thus, such findings will assist in the development of specific strategies for each Apoteca domain during the entire process of implementing drug dispensing.

Factors related to support from the community pharmacy chain were highlighted as facilitators of the implementation process. According to the literature, the support of the institution, the manager, and the supply of training, influence the provision of CPS in different settings [15, 26, 27, 36]. Regarding autonomy, studies have shown that this factor is influenced by the market economy, often limiting the capacity for professionals, who are employed, to apply their own judgement when making decisions [37, 38]. However, the fact that the community pharmacy supports patient care can empower pharmacists in their application of clinical activities and help improve patient care $[14,36,39]$. In this sense, all factors related to the support of the community pharmacy were related to the political domain of the Apoteca framework, which highlights the importance of strategies that engage managers throughout the CPS implementation process.

Factors related to the infrastructure of the community pharmacy were highlighted by the pharmacists. Studies indicate that the implementation of CPS must consider the presence of appropriate human, physical, and material resources conducive to professional practice [16, 39, 40, 41, 42]. Interestingly, the pharmacists reported deficiencies in their academic education in relation to drug dispensing. As in other low- and middle-income countries, these shortcomings may be related to an overemphasis of basic sciences during undergraduate studies and lack of specialized disciplines and internships for the development of clinical skills $[43,44,45,46]$. In addition, although there are government initiatives intent on modifying undergraduate degree programs related to health care, the excessive number of more than 600 pharmacy courses in Brazil can generate professional with different basic level needed to implement standard healthcare procedures $[3,47,48]$. These issues reinforce the need for curricular changes by educational institutions, specifically the insertion of clinical science aimed at patient care, as well as continuing education for community pharmacists.

The pharmacists pointed out factors related to the characteristics of the pharmacy, medicines, and other health products. In particular, the high number of patients using community pharmacies can compromise the quality of the drug dispensing, since the pharmacist may feel pressured to provide a quick service without the adequate provision of pharmaceutical counseling $[49,50]$. This factor is more apparent in community pharmacies that are located in large urban centers, due to the large number of people in the region [51], and may be related to the nature of drug dispensing as a service designed to serve all patients upon arrival (i.e., spontaneous demand). Other CPS, such as medication review and comprehensive medication management, facilitate the establishment and scheduling of patient eligibility criteria $[52,53]$. This implies that the implementation process of drug dispensing may present different challenges compared with the implementation of other CPS, and this will require the design of specific strategies for this service. 
Factors related to pharmacists, such as knowledge, skills, and attitudes, were described by the interviewees. These competencies must form the foundation of high-quality work processes and have been widely discussed in previous studies related to the implementation of CPS [25, 27, 34, 42]. Professions such as nursing, for example, which have well-defined work processes, establish competencies conducive to consistent and high-quality practices [54, 55]. Therefore, the development of patient-centered competences is essential for the establishment of performance standards for clinical activities and to strengthen pharmacists' professionalism in community pharmacies $[56,57,58]$. Thus, it is necessary to understand the individual and collective needs of pharmacists so that they may become competent in drug dispensing, by proposing interventions that optimize their performance.

The pharmacists reported the lack of structured work processes as a difficulty to them dispensing drugs efficiently. Studies have shown that the absence of defined, systematized, and reproducible work processes leads to varied pharmaceutical interventions in clinical practices, influencing the measure of the dispensing results $[59,60]$. On the other hand, the pharmacists highlighted the patient's feedback by telephone as a facilitator of the implementation of drug dispensing. The literature shows that, as well as the patient returning to the community pharmacy, a telephone call can be a viable alternative for evaluating the results of pharmaceutical interventions performed during drug dispensing, as long as indicators that assess the quality of these results are utilized $[18,61,62]$. Therefore, the use of instruments that support drug dispensing, and the establishment of performance indicators, can be important for the systematization of the dispensing process and should be used to ensure the reproducibility of the service.

The understanding of each pharmacy team member regarding their role and the existence of good relationships with the pharmacist were identified as facilitators in this study. According to the literature, for clinical activities to be carried out properly, it is important that the entire pharmacy team understands their roles and responsibilities, so as to ensure safe practice for the patient $[63,64]$. Furthermore, trusting relationships, collaboration, and good communication between team members are key to obtaining positive and measurable results that favor the implementation and sustainability of pharmacy services $[25,65,66]$. In this context of collaborative practices, it is important to develop performance indicators to evaluate the effectiveness and efficiency of the pharmacy team in their provision of health care.

The different factors related to the patient that were identified in this study were also addressed in previous studies. The literature shows that knowledge, beliefs, interest, skills, active involvement of the patient in their own care, literacy, and age of the patient can affect the use of services provided in community pharmacies $[67,68]$. Among the factors related to the patient's behavior, their view of the pharmacy as a setting of quick service was an interesting finding. Studies show that patients often misunderstand the pharmacist's role and do not see community pharmacies as healthcare facilities [25, $40,69]$. In contrast, in England, for example, there are initiatives within the health system that encourage the public to view the pharmacist in the community pharmacy as a primary point of care, ensuring patient safety $[70,71]$. Thus, a patient-centered approach by the pharmacist and informing patients about all 
available pharmacy services can be an valuable strategy to promote the visibility of community pharmacies and pharmacists.

To the best of our knowledge, this is the first study to identify factors that can influence the implementation of CPS with a focus on the drug dispensing service in community pharmacies, in which new factors that can influence this process were highlighted. As mentioned, the factors were categorized according to the Apoteca framework to allow for better planning of the strategies aimed at avoiding failures during the CPS implementation process. In addition, triangulation of data analysis methods was used to increase the reliability and quality of the results. However, there are certain limitations that must be mentioned. The perceptions of a single group of pharmacists are insufficient for comprehensively analyzing the complexity of a specific implementation context, even more so in a country with as many differences as Brazil.

\section{Conclusion}

The pharmacists interviewed herein identified several factors that may influence the implementation of drug dispensing in community pharmacies, such as a lack of systematization of the work process, deficiencies in their academic education, and the large number of patients using urban-based community pharmacies. Other factors such as support of the community pharmacy chain, adequate infrastructure, and good relationships within the pharmacy team and the pharmacist can positively influence the implementation of drug dispensing. In addition, the factors raised were allocated according to the Apoteca framework, evidencing the multifactorial nature of the implementation process. Therefore, these results can guide the planning of strategies aimed at improving the provision of drug dispensing in community pharmacies.

\section{Declarations}

\section{Ethics approval and consent to participate}

This study was approved by the Ethics Committee of the Federal University of Sergipe (CAAE: 15827719.4.0000.5546 and number 3.698.806).

\section{Consent for publication}

All participants signed a consent form that allowed voice recording and publication of interview data.

\section{Availability of data and materials}

The datasets generated and/or analysed during the current study are not publicly available due the Committee of Ethics in Research precludes the data sharing due to the need to protect the confidentiality of the participants. The datasets used in this analysis during the current study are available from the corresponding author on reasonable request. 


\section{Competing interests}

The authors declare that they have no competing interests.

\section{Funding}

This study was financed in part by the Coordination of Superior Level Staff Improvement (CAPES)Finance Code 001" and National Council for Scientific and Technological (CNPq). The funder had no role in in the design of the study and collection, analysis, and interpretation of data and in writing the manuscript.

\section{Authors' contributions}

SCS led the conception and design of the study, conducted the interviews, was closely involved in data analysis and interpretation, and wrote the manuscript. KSSR conducted the interviews, was closely involved in data analysis and interpretation and wrote the manuscript. DCSAA and GASJ were participated in data interpretation and revised the manuscript critically for important intellectual content. PWSM and JMS were involved in transcription of the interviews and data analysis. ARM was closely involved the conception and design of the study and conducted the interviews. DPLJ revised the manuscript critically for important intellectual content. All authors read and approved the final manuscript.

\section{Acknowledgments}

We are grateful to all pharmacists who participated in the interviews and to all pharmacy managers who agreed to conduct the interviews. Special thanks to the regional supervisor Thiago Siqueira Rodrigues, who supported the project in the community pharmacy chain.

\section{Abbreviations}

CPS- Clinical Pharmacy Services

SUS- Brazilian Health System

LEPFS- Research in Social Pharmacy

UFS- Federal University of Sergipe

COREQ- Consolidated Criteria for Reporting Qualitative Research

\section{References}

1. Martins SF, van Mil JWF, da Costa FA. The organizational framework of community pharmacies in Europe. Int J Clin Pharm. 2015 Oct 1;37(5):896-905. 
2. Payne K, Unni EJ, Jolley B. Impact of Dispensing Services in an Independent Community Pharmacy. Pharmacy. 2019;7(2):44.

3. Brasil. Conselho Federal de Farmácia. Dados 2018. https://www.cff.org.br/pagina.php? id=801\&menu=801\&titulo=Dados+2018(2018). Accessed $20 \mathrm{Jul} 2020$.

4. Alaqeel S, Abanmy NO. Counselling practices in community pharmacies in Riyadh, Saudi Arabia: a cross-sectional study. BMC Health Serv Res. 2015 Dec;15:557.

5. Ferreira TXAM, Prudente LR, Dewulf NDLS, Provin MP, Mastroianni PDC, da Silveira EA, et al. Medication dispensing as an opportunity for patient counseling and approach to drug-related problems. Brazilian J Pharm Sci. 2016;52(1):151-62.

6. Ibrahim MI, Palaian S, Al-Sulaiti F, El-Shami S. Evaluating community pharmacy practice in Qatar using simulated patient method:acute gastroenteritis management. Pharm Pract (Granada). 2016;14(4):800.

7. Moullin JC, Sabater-Hernández D, Benrimoj SI. Model for the evaluation of implementation programs and professional pharmacy services. Res Soc Adm Pharm. 2016;12(3):515-22.

8. Zardain E, Valle MO del, Loza MI, Garcia E, Lana A, Markham WA, et al. Psychosocial and behavioural determinants of the implementation of Pharmaceutical Care in Spain. 2009;174-82.

9. Eccles MP, Mittman BS. Welcome to Implementation Science. 2006;3:1-3.

10. Peters DH, Agyepong I. Implementation research: what it is and how to do it. 2013.

11. Garcia-Cardenas V, Perez-Escamilla B, Fernandez-Llimos F, Benrimoj SI. The complexity of implementation factors in professional pharmacy services. Vol. 14, Research in Social and Administrative Pharmacy. Elsevier Inc.; 2018. p. 498-500.

12. Hamilton $A B$, Finley EP. Qualitative methods in implementation research: An introduction. Psychiatry Res. 2019;280.

13. QualRIS. Qualitative Research in Implementation Science. Div Cancer Control Popul Sci Natl Cancer Institute.

14. Bacci JL, McGrath SH, Pringle JL, Maguire MA, McGivney MS. Implementation of targeted medication adherence interventions within a community chain pharmacy practice: The Pennsylvania Project. J Am Pharm Assoc. 2014;54(6):584-93.

15. Hattingh HL, Kelly F, Fowler J, Wheeler AJ. Implementation of a mental health medication management intervention in Australian community pharmacies: Facilitators and challenges. Res Soc Adm Pharm. 2017;13(5):969-79.

16. Marquis J, Schneider MP, Spencer B, Bugnon O, Du S. Exploring the implementation of a medication adherence programme by community pharmacists: a qualitative study. 2014;1014-22.

17. Cerqueira-Santos S, Rocha KSS, Boaventura TC, Jesus EMS, Silvestre CC, Alves BMCS, et al. Development and content validation of an instrument to document the dispensing of prescribed medicines. J Clin Pharm Ther. 2019;44(3). 
18. Rocha KSS, Cerqueira Santos S, Boaventura TC, dos Santos Júnior GA, de Araújo DCSA, Silvestre CC, et al. Development and content validation of an instrument to support pharmaceutical counselling for dispensing of prescribed medicines. J Eval Clin Pract. 2020;26(1).

19. De Castro MS, Correr CJ. Pharmaceutical care in community pharmacies: Practice and research in Brazil. Ann Pharmacother. 2007;41(9):1486-93.

20. Onozato T, Francisca dos Santos Cruz C, Milhome da Costa Farre AG, Silvestre CC, de Oliveira Santos Silva $R$, Araujo dos Santos Júnior $G$, et al. Factors influencing the implementation of clinical pharmacy services for hospitalized patients: A mixed-methods systematic review. Research in Social and Administrative Pharmacy. Elsevier Inc.; 2020:p. 437-49.

21. Santos Júnior GA, Silva ROS, Onozato T, Silvestre CC, Rocha KSS, Araujo EM, Lyra-Jr DP. Implementation of Clinical Pharmacy Services using Problematization with Maguerez Arc: a quasi experimental before - after study. J Eval Clinc Pract. DOI: 10.1111 / jep.13448.

22. Neusi Aparecida Navas, Berbel. A problematização e a aprendizagem baseada em problemas: 1998;139-54.

23. Bordenave JD, Pereira AM. Estratégias de ensino-aprendizagem. Estratégias de ensinoaprendizagem. 1982. p. 1-11.

24. Tong A, Sainsbury P, Craig J. Consolidated criteria for reporting qualitative research (COREQ): A 32item checklist for interviews and focus groups. Int J Qual Heal Care. 2007;19(6):349-57.

25. Dosea AS, Brito GC, Santos LMC, Marques TC, Balisa-Rocha B, Pimentel D, et al. Establishment, Implementation, and Consolidation of Clinical Pharmacy Services in Community Pharmacies: Perceptions of a Group of Pharmacists. Qual Health Res. 2017;27(3):363-73.

26. Ramos SF, Santos Júnior GA Dos, Pereira AM, Dosea AS, Rocha KSS, Pimentel DMM, et al. Facilitators and strategies to implement clinical pharmacy services in a metropolis in Northeast Brazil: A qualitative approach. BMC Health Serv Res. 2018;18(1):1-12.

27. Dos Santos Júnior GA, Ramos SF, Pereira A, Dosea AS, Araújo EM, Onozato T, et al. Perceived barriers to the implementation of clinical pharmacy services in a metropolis in Northeast Brazil. PLoS One. 2018;13(10):1-14.

28. Harry F W. Transforming Qualitative Data: Description, Analysis, and Interpretation. Thousand Oaks, CA. 1994.

29. Kyngäs SEH. The The qualitative content analysis process. n. Cole 1988, p. 107-115, 2007. qualitative content analysis process. 2007:107-15.

30. Hennink MM, Kaiser BN, Marconi VC. Code Saturation Versus Meaning Saturation: How Many Interviews Are Enough? Qual Health Res. 2017;27(4):591-608.

31. Ministério da Saúde. Portaria № 3.916, de 30 de outubro de 1998. https://bvsms.saude.gov.br/bvs/saudelegis/gm/1998/prt3916_30_10_1998.html (1998). Accessed $20 \mathrm{Jul} 2020$. 
32. Hernández A, Garcia-Delgado P, Garcia-Cardenas V, Ocaña A, Labrador E, Orera ML, et al. Characterization of patients' requests and pharmacists' professional practice in oropharyngeal condition in Spain. Int J Clin Pharm. 2015;37(2):300-9.

33. NHS - National Health Service. NHS Community Pharmacy services - a summary. http://psnc.org.uk/wp-content/uploads/2013/08/CPCF-summary-July-2013.pdf (2013). Accessed 20 Jul 2020.

34. Alcântara TDS, Onozato T, Araújo Neto FDC, Dosea AS, Cunha LC, De Araújo DCSA, et al. Perceptions of a group of hospital pharmacists and other professionals of the implementation of clinical pharmacy at a high complexity public hospital in Brazil. BMC Health Serv Res. 2018;18(1).

35. Peters DH, Adam T, Alonge O, Agyepong IA, Tran N. Republished research: Implementation research: What it is and how to do it. Br J Sports Med. 2014;48(8):731-6.

36. Ranghchian M, Sehat S, Akhgari M, Mehralian G. Performance model of community pharmacies in low-middle income countries: A societal perspective. J Retail Consum Serv. 2018;40:241-8.

37. Barros Da Silva W, Delizoicov D. Profissionalismo e desenvolvimento profissional: lições da sociologia das profissões para entender o processo de legitimação social da farmácia * Professionalism and professional development: lessons from the sociology of professions to understand the pro. Rev Bras Farm. 2009;90(1):27-34.

38. Elvey, R., Hassell, K., Lewis, P., Schafheutle, E., Willis, S., \& Harrison S. Patient-centred professionalism in pharmacy: values and behaviours. Eletronic Libr. 2015;34(1):1-5.

39. Doucette WR, Nevins JC, Gaither C, Kreling DH, Mott DA, Pedersen CA, et al. Organizational factors influencing pharmacy practice change. Res Soc Adm Pharm. 2012;8(4):274-84.

40. Hindi AMK, Schafheutle El, Jacobs S. Patient and public perspectives of community pharmacies in the United Kingdom: A systematic review. Heal Expect. 2018;21(2):409-28.

41. Santos-júnior GA, Marques TC, Silva ROS. Quality Indicators to Medication Review Services: Evaluation of the Structure Quality Indicators to Medication Review Services: Evaluation of the Structure. 2015.

42. Wibowo Y, Sunderland B, Hughes J. Pharmacist and physician perspectives on diabetes service delivery within community pharmacies in Indonesia: a qualitative study. Int J Pharm Pract. 2016 May;24(3):180-8.

43. Ahmed A, Tanveer M, Siddiqui A, Khan GM. Bridging the gap for clinical pharmacist in developing countries like Pakistan. Journal of the College of Physicians and Surgeons Pakistan. 2018: p. 22932.

44. Araújo DC, Barros IM, Mesquita AR. Communication skills in Brazilian pharmaceutical education: a documentary analysis. 2019;17(1):1-6.

45. Foppa AA, Martins GA, Nascimento RF, Mesquita AR, Chemello C. Experiential education in the pharmacy undergraduate curricula in Brazil. 2020;18(1):1-9.

46. Nunes-Da-Cunha I, Arguello B, Martinez FM, Fernandez-Llimos F. A comparison of patient-centered care in pharmacy curricula in the United States and Europe. Am J Pharm Educ. 2016;80(5). 
47. Brasil. Câmara de Educação Superior. Resolução CNE - CES 2, 19 de fevereiro de 2002. http://portal.mec.gov.br/cne/arquivos/pdf/CES032002.pdf (2002). Accessed 20 Jul 2020.

48. Brasil. Câmara de Educação Superior. Resolução CNE-CES Nº 6, de 19 de outubro de 2017. http://www.in.gov.br/materia/-/asset_publisher/Kujrw0TZC2Mb/content/id/19363913/do1-2017-1020-resolucao-n-6-de-19-de-outubro-de-2017-19363904 (2017). Accessed 20 Jul 2020.

49. Tinelli $M$, Ryan $M$, Bond $C$. Patients ' preferences for an increased pharmacist role in the management of drug therapy. 2009;275-82.

50. Porteous T, Ryan M, Bond C, Watson M, Watson V. Managing Minor Ailments; The Public 's Preferences for Attributes of Community Pharmacies . A Discrete Choice Experiment. 2016;1-15.

51. Howarth HD. Does rural and urban community pharmacy practice differ? A narrative systematic review. 2019;

52. Detoni KB, Martins M, Do G, Oliveira IV, Alves MR, Gonzáles MM, et al. Comprehensive medication management services in a Brazilian speciality pharmacy: a qualitative assessment. Int $\mathrm{J}$ Pharm Pharm Sci. 2017; 9(3).

53. Marques TC, Silva R de OS, Santos Júnior GA, Jesus Júnior FC, Silvestre CC, Rocha KSS, et al. Evaluation of process indicators of a medication review service between pharmacists and physicians. J Eval Clin Pract. 2019.

54. Garcia TR, Nóbrega MML da. Processo de enfermagem: da teoria à prática assistencial e de pesquisa. Esc Anna Nery. 2009;13(1):188-93.

55. Leal JAL, Melo CMM de. The nurses' work process in different countries: an integrative review. Rev Bras Enferm. 2018;71(2):413-23.

56. Erku DA, Belachew SA, Mekuria AB, Taye Haile K, Gebresillassie BM, Tegegn HG, et al. The role of community pharmacists in patient counseling and health education: a survey of their knowledge and level of involvement in relation to type 2 diabetes mellitus. Integr Pharm Res Pract. 2017;6:137-43.

57. Ilardo ML, Speciale A. The community pharmacist: Perceived barriers and patient-centered care communication. Int J Environ Res Public Health. 2020;17(2).

58. Surur AS, Getachew E, Teressa E, Hailemeskel B, Getaw NS, Erku DA. Self-reported and actual involvement of community pharmacists in patient counseling: A cross-sectional and simulated patient study in Gondar, Ethiopia. Pharm Pract (Granada). 2017;15(1):1-7.

59. Mobark DM. Assessing hormonal contraceptive dispensing and counseling provided by community pharmacists in the United Arab Emirates: a simulated patient study. 2019;17(2):8-14.

60. Puspitasari HP, Aslani P, Krass I. A review of counseling practices on prescription medicines in community pharmacies. Res Social Adm Pharm; 2009:197-210.

61. Kaae S, Pharm PD, Dam P, Sc MPH, Rossing C, Pharm PD. Evaluation of a pharmacy service helping patients to get a good start in taking their new medications for chronic diseases. Res Soc Adm Pharm. 2015. 
62. Stanton-robinson C, Al-jumaili AA, Jackson A, Catney C, Veach S, Witry MJ. Journal of the American Pharmacists Association Evaluation of community pharmacist e provided telephone interventions to improve adherence to hypertension and diabetes medications. J Am Pharm Assoc. 2018;1-5.

63. Donald M, King-Shier K, Tsuyuki RT, Al Hamarneh YN, Jones CA, Manns B, et al. Patient, family physician and community pharmacist perspectives on expanded pharmacy scope of practice: a qualitative study. C Open. 2017;5(1):E205-12.

64. Jacobs S, Johnson S, Hassell K. Managing workplace stress in community pharmacy organisations: lessons from a review of the wider stress management and prevention literature. Int $\mathrm{J}$ Pharm Pract. 2018;26(1):28-38.

65. Bacci JL, Coley KC, McGrath K, Abraham O, Adams AJ, McGivney MS. Strategies to facilitate the implementation of collaborative practice agreements in chain community pharmacies. J Am Pharm Assoc. 2016;56(3):257-265.e2.

66. Phipps DL, Jones CEL, Parker D, Ashcroft DM. Organizational conditions for engagement in quality and safety improvement: A longitudinal qualitative study of community pharmacies. BMC Health Serv Res. 2018;18(1):1-10.

67. Hossain LN, Fernandez-llimos F, Luckett T, Moullin JC, Durks D, Franco-trigo L, et al. Qualitative metasynthesis of barriers and facilitators that influence the implementation of community pharmacy services: perspectives of patients, nurses and general medical practitioners. 2017.

68. Maes KA, Jasmine A. Ruppanner, Tamara L. Imfeld-Isenegger KEH, Lampert ML, Boeni F. Dispensing of Prescribed Medicines in Swiss Counselling Activities. 2018;1-16.

69. Eades CE, Ferguson JS, O'Carroll RE. Public health in community pharmacy: A systematic review of pharmacist and consumer views. BMC Public Health. 2011;11.

70. Goundrey-Smith S. The connected community pharmacy: Benefits for healthcare and implications for health policy. Front Pharmacol. 2018;9:1-10.

71. PSNC. Pharmaceutical Services Negotiating Committee P. About community pharmacy. https://psnc.org.uk/psncs-work/about-community-pharmacy/. Accessed 20 Jul 2020.

\section{Tables}

Table 1. Characteristics of pharmacists who participated of implementation of drug dispensing $(n=18)$ 


\begin{tabular}{|ll|}
\hline Characteristc & N (\%) \\
\hline Sex & $16(89 \%)$ \\
\hline Female & $2(11 \%)$ \\
\hline Educational institution where graduated & \\
\hline Public & $10(55.5 \%)$ \\
\hline Private & $8(44.5 \%)$ \\
\hline Postgraduate degree & $5(28 \%)$ \\
\hline Yes & $13(72 \%)$ \\
\hline No & \\
\hline Age (years) & $27.8(3.7)$ \\
\hline Time of graduation (years) & $4(2.8)$ \\
\hline Working time in the institution (years) & $2.1(0.9)$ \\
\hline
\end{tabular}

Table 2. Factors that can influence the implementation of drug dispensing in community pharmacies, classified according to the Apoteca framework. 


\begin{tabular}{|c|c|c|}
\hline Category & Subcategory & Factors \\
\hline \multirow[t]{4}{*}{$\begin{array}{l}\text { Support from community } \\
\text { pharmacy chain }\end{array}$} & \multirow[t]{4}{*}{-} & $\begin{array}{l}\text { Institutional policy of the community } \\
\text { pharmacy chain }(P)\end{array}$ \\
\hline & & Support of the managers $(P)$ \\
\hline & & $\begin{array}{l}\text { Supply of training by the community } \\
\text { pharmacy chain }(P)\end{array}$ \\
\hline & & $\begin{array}{l}\text { Guaranteed autonomy of pharmacists by } \\
\text { the pharmacy/ managers }(P)\end{array}$ \\
\hline \multirow[t]{11}{*}{ Pharmacy infrastructure } & $\begin{array}{l}\text { Physical } \\
\text { resources }\end{array}$ & $\begin{array}{l}\text { Structure available for performing drug } \\
\text { dispensing }(A)\end{array}$ \\
\hline & \multirow[t]{4}{*}{$\begin{array}{l}\text { Material } \\
\text { resources }\end{array}$} & $\begin{array}{l}\text { Availability of technology (computer, cell } \\
\text { phone, system) }(A)\end{array}$ \\
\hline & & Availability of information sources (A) \\
\hline & & Availability of patient information (A) \\
\hline & & $\begin{array}{l}\text { Availability of medicine at the community } \\
\text { pharmacy }(A)\end{array}$ \\
\hline & \multirow{2}{*}{$\begin{array}{l}\text { Human } \\
\text { resources - } \\
\text { Number }\end{array}$} & $\begin{array}{l}\text { Number of pharmacists at the community } \\
\text { pharmacy }(A)\end{array}$ \\
\hline & & $\begin{array}{l}\text { Number of pharmacy attendants at the } \\
\text { community pharmacy }(A)\end{array}$ \\
\hline & \multirow[t]{4}{*}{$\begin{array}{l}\text { Human } \\
\text { resources - } \\
\text { Qualification }\end{array}$} & $\begin{array}{l}\text { Pharmacist's academic education with } \\
\text { emphasis on clinical activities }(\mathrm{T})\end{array}$ \\
\hline & & Pharmacist's practical experience $(\mathrm{T})$ \\
\hline & & Pharmacist continuing education $(\mathrm{T})$ \\
\hline & & $\begin{array}{l}\text { Pharmacy manager's academic education } \\
(\mathrm{T})\end{array}$ \\
\hline \multirow{4}{*}{$\begin{array}{l}\text { Characteristics of the pharmacy, } \\
\text { medicines, and other health } \\
\text { products }\end{array}$} & \multirow{4}{*}{-} & Pharmacy location (A) \\
\hline & & $\begin{array}{l}\text { Large number of patients using the } \\
\text { community pharmacy }(A)\end{array}$ \\
\hline & & Dosage form $(A)$ \\
\hline & & $\begin{array}{l}\text { Range of medicines and health products in } \\
\text { the market }(A)\end{array}$ \\
\hline \multirow[t]{2}{*}{ Pharmacist } & Responsibilities & $\begin{array}{l}\text { Number of activities to be developed by } \\
\text { pharmacists (clinical and logistical } \\
\text { activities) (A) }\end{array}$ \\
\hline & Knowledge & $\begin{array}{l}\text { Understanding of clinical pharmacy services } \\
(\mathrm{T})\end{array}$ \\
\hline
\end{tabular}


Pharmaceutical legislation ( $\mathrm{T}$ )

Pharmacotherapy $(\mathrm{T})$

Foreign language $(T)$

Clinical skills Communication $(T)$

Clinical decision making $(\mathrm{T})$

Attitude

(At)

Pharmacist self-confidence (At)

Pharmacist initiative (At)

Collaboration between pharmacists (At)

Motivation Patient feedback (At)

Bond/therapeutic relationship between the pharmacist and the patient (At)

Patient trust in the pharmacist (At)

Recognition of the pharmacist's leadership by the team (At)

Professional satisfaction (At)

Dispens work process

Systematization of the drug dispensing process $(A)$

Obtaining patient feedback (A)

Pharmacy team

Understanding of role within the team $(T)$

Relationship with the pharmacist $(P)$

Patient

Characteristics

Previous knowledge of pharmacotherapy in use $(T)$

Literacy $(\mathrm{T})$

Age of the patient/special conditions $(T)$

Behavior

Interest in receiving drug dispensing (At)

Active participation in the dispensing (At)

View of the pharmacy as a setting of quick service $(T)$

Expectations regarding pharmacist care (At)

Individual who purchases the medicine (At)

Apoteca domains: $\mathrm{A}=$ administrative, $\mathrm{P}=$ political, $\mathrm{T}=$ technical, $\mathrm{At}=$ attitudinal . 


\section{Supplementary Files}

This is a list of supplementary files associated with this preprint. Click to download.

- Appendixtopicssemistructuredinterviews.docx

- Appendixtopicssemistructuredinterviews.docx

- ChecklistCOREQ.docx

- ChecklistCOREQ.docx 